\title{
LOS USOS MONETARIOS Y LAS PRÁCTICAS FINANCIERAS. CÓRDOBA, ARGENTINA 1850-1900
}

\author{
Félix Converso*
}

\begin{abstract}
$\mathrm{A}$ 1 abordar el tema inherente a la problemática provocada por el uso de diversas monedas en las plazas mercantiles regionales durante la segunda mitad del siglo XIX, conviene considerar que la función de medio de cambio puede tolerar la presencia de más de una moneda sin demasiadas complicaciones, pero la función de unidad de cuenta no la permite.

Para desempeñar eficientemente esta función se necesita una moneda única. En los márgenes del mercado pueden utilizarse varias monedas para comprar los mismo bienes, pero para conseguir que un sistema con distintos medios de pago funcione medianamente bien, las relaciones entre ellos deben ser fijas, aunque en la práctica estos vínculos son difíciles de mantener. ${ }^{1}$

Las dificultades surgen cuando el valor relativo de las dos o más monedas en uso se cambia periódicamente. Precisamente las alteraciones en los valores monetarios, sufridas a lo largo de los decenios que aborda este intento de comprensión de algunos problemas peculiares a la historia económica, entorpecieron el intercambio mercantil regional.

Las transacciones de mercado que suponen la existencia de dinero, pueden fallar por fenómenos monetarios y pueden tomar caminos obli-

* Consejo Nacional de Investigaciones Científicas y Técnicas y Universidad Nacional de Córdoba.

${ }^{1}$ Charles P. Kindleberger, Historia financiera de Europa, Editorial Crítica, Barcelona, 1988, pp. 78-79.
\end{abstract}


gados en razón de consideraciones relacionadas con el dinero, provocando variaciones en los hábitos mercantiles adquiridos.

No obstante, no puede olvidarse a -los efectos de este análisis- que los mercados frecuentemente disponen la adopción de medidas correctoras de las deficiencias generadas en las propuestas formales de los Estados. Las desestructuran y las adecuan a las necesidades del intercambio.

\section{BREVE COMENTARIO SOBRE LAS FUENTES}

Pocos son los trabajos dedicados al tema de la moneda y las finanzas en la Argentina del siglo XIX. Quizás la historia monetaria más actualizada con visión nacional sea el libro de Roberto Cortés Conde, Dinero, deuda y crisis. Evolución fiscal y monetaria en Argentina, Buenos Aires, 1989. Recientemente la Academia Nacional de la Historia publicó un artículo que fue escrito en colaboración por el autor mencionado, A. I. Ferreyra, Luis Coria, Enrique Schaller y quien esto escribe, titulado "Las finanzas públicas y la moneda en las provincias del interior (1810-1860)", tomo 5 de la Nueva historia de la nación argentina, Buenos Aires 2000, y constituye un primer acercamiento al tema en ese periodo.

Sobre la región interior de Argentina, y particularmente referido al tema específico de la moneda, sólo existía el libro de Carlos Segreti, Moneda y política en la primera mitad del siglo XIX. Contribución al estudio de la historia de la moneda argentina, Tucumán, 1975, un aporte de un excelente historiador, pero no especializado en historia económica, que con su trabajo ayudaba a esclarecer algunos problemas de la política en vinculación a la moneda.

En relación con las finanzas públicas durante la primera mitad del siglo XIX, un par de libros deben mencionarse. Tulio Halperin Donghi en Guerra y finanzas en los orígenes del Estado argentino (1791-1850), Buenos Aires, 1982, hizo algunas referencias a esta problemática en el interior. Años después, José Carlos Chiaramonte con Mercaderes del litoral. Economía y sociedad en la provincia de Corrientes, primera mitad del siglo XIX, Buenos Aires, 1991, comenzó los estudios peculiares en la provincia de Corrientes. En un interesante artículo Roberto Schmit, "El comercio y las finanzas públicas en los estados provinciales", en Revolución, República, Confederación (1806-1852), Buenos Aires, enfocó el tema en el litoral argentino. Por mi parte, publiqué un par de artículos respecto al tema y al periodo referido. ${ }^{2}$ Posteriormente Silvia Romano en "Finanzas públicas de la pro-

${ }^{2}$ Véase nota 94. 
vincia de Córdoba 1830-1855", Boletín del Instituto de Historia Argentina, Dr. Emilio Ravignani, núm. 5, Buenos Aires, 1992, hizo su aporte sobre estos estudios, todos, con epicentro en Córdoba.

Para la segunda mitad del siglo decimonónico, en lo inherente al tema específico de la moneda, aún no se ha concretado un estudio medianamente completo dedicado al interior de Argentina.

Entre tanto avanzaban mis investigaciones centradas en el comercio regional, con un enfoque particular en Córdoba durante la segunda mitad del siglo XIX. A medida que lo hacía surgieron serias interrogantes y planteos inherentes a los inconvenientes que suscitaba la diversidad monetaria vigente, en función de la unidad de cuenta.

Estos problemas afectaban peculiarmente al mercado cordobés, que por su privilegiada situación geográfica, en la región central de Argentina, lo mantenía permanentemente vinculado a las plazas mercantiles situados en los diversos espacios del intercambio, habituado a la diversidad monetaria, pero con la cuestión inherente a las equivalencias irresuelta durante la mayor parte del periodo. Creando situaciones confusas respecto de la unidad de cuenta.

En este punto comenzó mi mayor dificultad para responder las preguntas que me formulaba el conocimiento de la cuestión, tangencialmente al tema central investigado íntimamente vinculado al monetario, ¿dónde conseguir fuentes más o menos completas idóneas para elaborar explicaciones rápidamente? Debo confesar que con estas características no las hallé, por tanto, recurrí a la búsqueda de la información proporcionada por toda clase de documentos históricos custodiados en los diversos repositorios a los que tuve acceso.

Debí entonces apelar a las fuentes primarias y a los periódicos de la época. Ambas alternativas suponen un lento y meticuloso trabajo de revisión documental, porque, sobre todo en las fuentes primarias, la información -relacionada al tema moneda y finanzas- solía registrarse de forma indirecta, a veces sesgada. En pocas ocasiones se anotaban referencias específicas, salvo en los casos de demandas judiciales incoadas contra determinados bancos en procura del cobro de créditos en moneda determinada, en periodos afectados por el plurimonetarismo circulante, agravado por la carencia de equivalencias oficialmente reconocidas.

Siempre siguiendo en la búsqueda de fuentes primarias, fue posible relevar información relacionada con los problemas monetarios y financieros en litigios comerciales y en escrituras en las que se protocolizaban créditos o préstamos diversos, en esta documentación, en algunas ocasiones, se consignaban equivalencias convencionales acordadas entre las partes contratantes. 


\section{Félix Converso}

Respecto a la información obtenida de los periódicos de la época, si bien resulta útil, conviene imponerles un tratamiento cuidadoso, dado su carácter marcadamente impresionista, no siempre creíble o ajustado a la realidad, razón por la cual su cotejo con otro tipo de fuentes -en caso de hallarlas- es esencial e ineludible. El cruce de información resulta fundamental para construir la historia de los temas monetarios.

Otro tipo de fuentes, en este caso editadas, tales como la revisión de cuerpos legales, códigos, compilaciones, leyes, etc., no informan más allá de las disposiciones formales del Estado, las que resultan siempre útiles a la hora de indicar la interrelación vigente entre aquél y el mercado, aunque no siempre cuando se trata de la deuda pública, tan sensible a algunos agentes mercantiles acreedores del Estado. A propósito de este aspecto, conviene señalar que el periodo de 1850 hasta 1870 , fue anotado con poca claridad.

En lo inherente a las fuentes primarias en que se pueden analizar los créditos otorgados por particulares o específicamente de comerciantes mayoristas a minoristas o a clientes -ya fuesen préstamos encubiertos o no, a veces abiertamente usurarios- no conviene generalizar y deben tratarse con especial cuidado los pactos protocolizados, porque estos no siempre se concibieron como parte de la real operación transaccional. En efecto, en las fuentes protocolizadas se asentaron contratos en los que ambas partes acordaron registrar sólo parte de lo pactado, pero este hecho por fuera del contenido en el documento, el papel del usurario marcaba exigencias no escritas que el acreedor en su urgencia transaccional aceptaba, tales como pactos de retroventa, capitalización de intereses, adeudados.

En fin, no es aconsejable realizar un estudio de estos temas, particularmente enfocados al interior regional durante el siglo XIX, sin emprender una previa labor de búsqueda intensa y pormenorizada de fuentes primarias. Una vez relevada la información local -por denominarla de alguna manera- resulta muy provechoso cotejarla y relacionarla con la obtenida en plazas mercantiles vinculadas al intercambio interregional de la época.

\section{COMERCIO Y MONEDAS: SUS PROBLEMAS}

La evolución de la operatoria mercantil reconoce una vinculación con el proceso de desarrollo de la moneda en función de medio de pago, y su indagación señala la preponderancia, en las plazas del interior, del uso de la moneda metálica en relación con la emitida en billete papel.

Este predominio se proyecta hasta los comienzos de la década de 1880 , en el caso particular de la plaza cordobesa. En efecto, en octubre 
de 1882, el comercio y la banca de Córdoba aún consideraban al peso plata boliviano como "la única moneda efectiva circulante entre nosotros, su desaparición en un plazo relativamente corto[...] produciría conflictos que pueden ser de fatales consecuencias y comprometerían seriamente el estado económico de esta provincia". ${ }^{3}$

La pluralidad de monedas en uso es una de las agudas dificultades que el sector dedicado al intercambio mercantil debió sortear. Esta diversidad monetaria trazaba una distinción en la operatoria del interior con la realizada en Buenos Aires, y en algunas transacciones determinaba un crecimiento de los costos, que a su vez aumentaban los precios. ${ }^{4}$

El hábito prevalente de transar en metálico es evidente en distintas épocas y circunstancias. Por ejemplo, a fines del decenio de 1820 , cuando los comerciantes de Córdoba expresaron una cerrada negativa a recibir los billetes papel emitidos por el Banco Nacional, obligando a los encargados de las proveedurías a los ejércitos en tránsito a munirse de moneda circulante en el interior del país para realizar las compras necesarias. ${ }^{5}$

Este uso del metálico estaba tan asumido que el comercio interregional, ante la escasez del numerario, circulaba ocasionalmente moneda feble, prefiriéndola al billete papel aún en conocimiento de los perjuicios que ocasionaban estas maniobras. A punto tal que a comienzos de 1830 , cierto segmento mercantil manejaba moneda falsa procedente de Tucumán, imitación de la acuñada en La Rioja ${ }^{6}$

La consuetudinaria operatoria monetaria del comercio de las plazas del centro y norte del país se extendió eventualmente al litoral. En efecto, los vínculos comerciales trazados con el litoral comenzaron a presentar una paulatina intensificación como consecuencia de los bloqueos francés e inglés al puerto de Buenos Aires, cuando la plaza de Córdoba optó por el recurso de proveerse y comerciar con mercados alternativos. ${ }^{7}$ Estas operaciones explican el avance del uso de la moneda boliviana sobre aquellas plazas, así como aquellas de acuñación riojana y cordobesa, durante la década de 1840 .

${ }^{3}$ Archivo Histórico de la Provincia de Córdoba (en adelante AHPC), 1882, Gobierno, t. 7, fs. $142-149$.

${ }^{4}$ En el convenio pactado entre Carlos Grand y José Cortés Funes, representante de Gabriel Chevallier de Buenos Aires, fechado el 25 de febrero de 1865 se lee: "sobre el valor de factura se cargará $47 \%$ por los gastos y costos que puestos en Córdoba tienen las mercaderías despachadas en Buenos Aires", AHPC, 1865, Juzgado 1a. Nominación Comercial, leg. 17, exp. 4. $317-319$

${ }^{5}$ José María Paz, Memorias póstumas, Editorial Almafuerte, Buenos Aires, 1957, t. II, pp.

${ }^{6}$ AHPC, 1829-1831, Registro Oficial, t. 1, f. 17.

${ }^{7}$ Félix Converso, Relaciones del intercambio, acrecentamiento patrimonial e inversión del capital comercial, Centro de Estudios Históricos, Córdoba, 1991, pp. 58-60 (Colección Cuadernos de Avances de Trabajos de Investigación, núm. 2). 
El recelo relacionado con el eventual uso de moneda papel recreó un episodio similar al aludido anteriormente suscitado en el decenio de 1820. Poco más de 30 años transcurrieron, cuando al disponer el gobierno cordobés la supresión del cobro de los derechos de aduana, se produjo una falencia fiscal en la provincia de Córdoba. Una vez comprobada, se buscó auxilio a los efectos de solventarla, en consecuencia durante los años 1853 y 1854 , el gobierno de la Confederación puso a disposición de la tesorería de Córdoba remesas mensuales por un valor de 9000 pesos. $^{8}$ Envíos que no siempre se cumplieron.

El resultado en la circulación de los denominados "papeles de Fragueiro" fue ínfimo, porque estos billetes emitidos por el Banco Nacional de la Confederación fueron recibidos con evidente desconfianza y falta de aceptación, rechazo que se acentuó en las zonas de fronteras, particularmente las situadas al norte y sur de la provincia. ${ }^{9}$

Por su parte, el sector comercial mostrando suspicacia respecto de un papel moneda que no lograba su aceptación a la par, cuyo uso suscitaba sospechas y presagiaba modificaciones en la operatoria de los mercados regionales, poca o ninguna admisión le otorgó. ${ }^{10}$

Otra hubiera sido la postura mercantil ante la posibilidad cierta de la convertibilidad en metálico de los billetes del banco. Por el contrario, la devaluación que acusó ese circulante al causar la consecuente disminución del poder adquisitivo del volumen de mercancías, significó la resistencia del comercio a la utilización como medio de pago de la moneda papel.

Rechazo que muestra la conducta asumida por el comercio ante la falta de respaldo estatal, cuando los organismos financieros de la Confederación no pudieron competir con la capacidad financiera de la provincia de Buenos Aires. Esta falencia motivó el derrumbe de las estructuras institucionales que se pretendió construir y produjo como consecuencia el cese de la emisión del mencionado papel moneda.

A fines de 1854 se reconoció una depreciación del billete, que en el lapso transcurrido entre agosto a diciembre evidenció una baja del orden de 31 a 58\%, consecuentemente produjo dificultades en las transacciones de la plaza Córdoba y en las regionales, constituyendo otro elemento negativo que se sumó para acentuar la resistencia del comercio a la circulación del billete. ${ }^{11}$

La diversidad de monedas en uso generó dificultades esporádicas que repercutieron en el tráfico establecido entre los mercados regionales y la

${ }^{8}$ AHPC, 1853, Gobierno, caja 230; 1854, cajas 235 y 236, y Hacienda, 1854, t. 635.

${ }^{9}$ Ibid., 1854, caja 236 , fs. 54 y 633.

${ }^{10} \mathrm{Ibid}$., fs. 607 y 634 .

${ }^{11}$ Ibid., fs. 88 y 166 , y Hacienda, t. 269, f. 60. 
plaza de Buenos Aires. Estos problemas fueron provocados por la vigencia y coexistencia de medios de pago con características diferentes y con indisimulable afectación de la circulación mercantil en el interior. En estos núcleos mercantiles se constata la entidad otorgada al peso plata, sobre todo el boliviano, particularmente desde el decenio de 1850, a la vez que el peso papel se usaba en la provincia de Buenos Aires.

Además, en Córdoba, durante los primeros años del decenio de 1850 continuó la utilización de la moneda cordobesa de plata, acuñada entre 1844 y 1852, aunque no alcanzaba a la circulación de la moneda boliviana, que predominaba a pesar de su poco valor.

La operatividad en el circuito Córdoba-Buenos Aires no resultó sencilla a causa del valor intrínseco inferior al nominal que afectaba a la moneda boliviana, esto se explica al considerar las deficiencias en su acuñación que en la práctica provocaba descuentos sobre este valor.

$\mathrm{El}$ sector mercantil de las provincias del interior evidenció cuidado extremo en la apreciación de la moneda utilizada en las transacciones que proyectaba realizar en determinadas plazas, estimando cautelosamente el demérito potencial o la vigencia ocasional de la depreciación del medio de pago en cuestión. En 1853 las contingencias políticas llevaron a Urquiza a trabar e imposibilitar el tráfico directo con Buenos Aires, el comercio de Córdoba vislumbró la posibilidad de realizar ventas de lanas en el puerto de Montevideo, pero los agentes mercantiles dudaron en concretar la operación "porque allí no se venden a onzas de oro, sino a moneda del país, aquella moneda es lo mismo que la nuestra cordobesa y tiene un demérito de $6 \%$ para reducirla a onza de oro, motivo por el que nadie resuelve mandarlas alli”. ${ }^{12}$

El problema de la depreciación de la moneda de cuño local despertó cierta cautela en las transacciones operadas en determinadas plazas mercantiles, e impidió la realización de operaciones que podían posibilitar la viabilidad de nuevos circuitos alternativos, como en el caso aludido anteriormente.

En otro contexto, las dificultades originadas fuera del país también afectaron la balanza del comercio regional, al precipitarse la crisis mundial de 1857. En el mercado rioplatense se produjo la declinación de la demanda de materias primas y la consiguiente devaluación de los productos argentinos exportables, cayendo los precios. ${ }^{13}$

${ }^{12}$ AHPC, 1853, Gobierno, caja 230, carp. 5, f. 691.

${ }^{13}$ Juan Âlvarez, Guerra económica entre la Confederación y Buenos Aires, 1852-1861, Academia Nacional de la Historia, Historia de la Nación Argentina, Buenos Aires, 1962, t. viII, pp. 121 y 123. 
La plaza cordobesa no se sustrajo a estos acontecimientos, aunque presentó matices comparativamente favorables. Esto puede inferirse de la crónica de la época, que al referir las repercusiones de la crisis en los mercados de Buenos Aires y Montevideo sostenía que

esto no sucede en nuestro país [Córdoba] porque siendo los valores exportados en productos naturales, mucho menores que los importados en mercaderías, no se hace preciso tanto metálico, y las transacciones se hacen con capitales propios[...] Los valores importados [de granos] no sobrepasaron los exportados porque en 1857, en que se declaró esta crisis la importación ha sido reducidísima, mientras la exportación puede considerarse duplicada, ya por el aumento de las especies, como por la exorbitante suba de sus valores. ${ }^{14}$

Expresado en otros términos, la crisis mundial circunstancialmente no afectó de inmediato la habitual circulación de metálico en el interior, particularmente en la plaza de Córdoba, porque las buenas cosechas -poco frecuentes y de ínfima cuantía en esa época- permitieron reunir reservas de granos, que en alguna medida protegió la masa de metálico que se hubiera necesitado en caso de mayor demanda de cereales. ${ }^{15}$

Pero la carencia de circulante, peculiarmente de la moneda de oro observada en las plazas portuarias, influyó en el interior en la determinación del tipo o tasa de interés aplicadas para financiar la falta de capitales que afectaba al sector mercantil de Córdoba. ${ }^{16}$

\section{LA MERMA DEL CIRCULANTE}

Esta ausencia de dinero en el mercado fue explicada por la existencia de una considerable masa de metálico inmovilizada, sin inversión en la producción y falta de colocación en la circulación. Esta inmovilización de capitales se imputó -en su momento- a la inacción de los productores de la campaña, quienes al conseguir réditos importantes, fruto del coyuntural crecimiento producido en el valor del ganado en pie, no canalizaron esos beneficios en otras inversiones, no midieron los costos de oportunidades, posiblemente a causa de la ignorancia que se les atribuía por encontrarse espacialmente alejados de los centros mercantiles.

Aunque no siempre sucedió esto por causas que puedan atribuirse a la ignorancia de las potenciales operatorias. Debe considerarse que en

${ }^{14}$ El Imparcial, Córdoba, 29 de septiembre de 1857, año III, núm. 433.

${ }^{15}$ Ibid., 24 de mayo de 1857, año III, núm. 332: "se comprende que la moneda disminuya cuando siendo mala la cosecha se hagan fuertes importaciones de granos, porque faltaría la masa de metálico que se utilizó para pagar".

${ }^{16}$ Ibid., 12 de octubre de 1857, año III, núm. 470. 
esta época prácticamente no existía una producción agrícola comercial, se encontraba ausente la actividad que podría haber brindado un mayor ingreso e inducido a los campesinos a recurrir al mercado más asiduamente para satisfacer sus necesidades y tomar los riesgos que implicaba afrontar el desarrollo de una cosecha comercial.

Para sentirse seguro, el campesino buscaba cierto aislamiento de la economía monetaria, no contraía deudas y adecuaba los gastos a la propia producción. Estas características daban por resultado la resistencia a solicitar dinero a préstamo o invertir capitales en la producción manufacturera de la ciudad.

Entonces, como los riesgos que implicaron los escasos emprendimientos agropecuarios fueron tan importantes que significaron episodios de inseguridad para quienes los soportaban, se prefería optar por aquello que se consideraba más certero y que denotaba algún aislacionismo monetario y financiero. En definitiva, estas conductas significaron una simple respuesta institucional -en tanto chacra o pequeña estancia- efectiva ante la ausencia de cualquier otro método para disminuir los riesgos aludidos. ${ }^{17}$

A las mencionadas particularidades se agregaba la ancestral desconfianza del productor campesino, que retaceaba su dinero por temor a perderlo en operaciones que se les antojaban oscuras y desprovistas de las garantías esperadas. Por otra parte, los comerciantes citadinos que actuaban como financistas o tomadores a préstamo de estos pequeños capitales, no siempre lograron llevar a cabo las pretensiones del potencial inversor campesino. ${ }^{18}$

En tanto, los sectores pobres y menesterosos, se encontraron afectados en otro aspecto relacionado con el intercambio mercantil y el medio de pago, porque la carencia de moneda de pequeña denominación provocó impedimentos en la satisfacción de las necesidades de su consumo y posibilitó la especulación del comercio proveedor. ${ }^{19}$

${ }^{17}$ Para construir esta explicación se han seguido algunas teorías anotadas por Jon Cohen, "Institutions and economics analysis" en Thomas Rawski, Susan Carter, Jon Cohen et al., Economics and the historian, University of California Press, California, 1996.

${ }^{18}$ El Imparcial, Córdoba, 29 de mayo de 1857, año III, núm. 332, y 29 de septiembre de 1857, año II, núm. 433, en estas notas periodísticas se hacía hincapié en la necesidad de las instituciones bancarias para canalizar estos capitales inmovilizados.

${ }^{19}$ Un informe, fechado el 13 de noviembre de 1857, producido por el gobernador Roque Ferreyra, de extracción mercantil y por tanto conocedor privilegiado, se detuvo en algunos detalles del problema: "El comerciante que siempre especula sobre la necesidad, detiene al necesitado consumidor todo un medio peso, cuando sólo va a invertir un cuartillo y so pretexto de carecer de cambio le obliga a emplearle más de lo que necesita, o a que deje la moneda y vaya sacando paulatinamente su valor en especies a un precio exorbitante que no le han sido precisado o que podía tomarlos en otra parte mejores y acomodadas[...] en último resultado viene a perder el menesteroso", AHPC, 1857, caja 241, carp. 1, fs. 29-30. 
La merma de circulante en el mercado cordobés se reiteró durante 1863, como consecuencia de un proceso de disminución progresiva suscitada a lo largo de los primeros años de la década, lapso en que las pugnas político-bélicas incidieron en la disminución de inversiones. Abonando esta afirmación, en la época quizás con cierta exageración, se calculó alrededor de 5000000 el capital líquido retirado del circuito comercial. $^{20}$

Tres años despuês, la disminución progresiva hasta llegar a una palmaria carencia de circulación del papel moneda que se presentó en la plaza de Buenos Aires, ${ }^{21}$ exhibió su correlato en el mercado regional interior. ${ }^{22}$

En este episodio, la valorización del papel moneda en el puerto rioplatense favoreció en dicha plaza a los comerciantes importadores, pero perjudicó a los productores ganaderos y al comercio de exportación en general. ${ }^{23}$ En Córdoba, esta crisis afectó al importante sector que comerciaba regularmente con las plazas de Buenos Aires y Montevideo ${ }^{24}$ en consecuencia, en los mercados regionales del interior, algunos productos sufrieron bajas en sus precios, tal fue el caso de las lanas. En efecto, el promedio anual de las cotizaciones de la lana en la plaza de la ciudad de Córdoba, descendió a partir de 1867 hasta los comienzos de la siguiente década. ${ }^{25}$

Una vez superado el problema monetario, se constataron los beneficios que este tráfico reportaba. En 1871, la crónica periodística informaba:

mucho antes de la esquila los compradores se apresuraron a recorrer la campaña comprometiendo las partidas por el 15 y el $20 \%$ más que el año pasado, ahora los especuladores ante la noticia de la demanda europea y consiguiente suba de precios, se alcanzaron a comprar pagando hasta 80 y $90 \%$ más que el año pasado[...]Sabemos de lanas regulares que en la esquila pasada se vendieron a 17 reales bolivianos, hoy se compra a 30 reales bolivianos, recibiéndolas en el campo. ${ }^{26}$

${ }^{20}$ El Eco de Córdoba, Córdoba, 13 de octubre de 1863, 2a. época, año II, núm. 258.

${ }^{21}$ Roberto Cortés Conde, Dinero, deuda y crisis. Evolución fiscal y monetaria en la Argentina, Cortés Conde/Editorial Sudamericana, Buenos Aires, 1989, pp. 47-48.

${ }^{22}$ Las Provincias, Córdoba, 17 de octubre de 1866, año I, núm. 40.

${ }^{23}$ José Carlos Chiaramonte, Nacionalismo y liberalismo económico en Argentina 1860-1880, Editorial Solar/Hachette, Buenos Aires, 1971, p. 59.

${ }^{24}$ Refiriéndose a esta situación el fuerte comerciante Seferino de la Lastra explicaba a su hermano y corresponsal Nilamón de la Lastra: "no hay quien quiera vender sus existencias por ningún precio, por no tomar los billetes de banco", en Fondo Documental del Instituto de Estudios Americanistas (IEA), documento núm. 1965.

${ }^{25}$ El Eco de Córdoba, Córdoba, 1 de mayo de 1866, 2a. época, año Iv, núm. 999; 3 de julio de 1866, núm. 1049; 8 de agosto de 1866, núm. 1079; Las Provincias, Córdoba, 17 de agosto de 1866, año I, núm. 7.

${ }^{26}$ El Eco de Córdoba, Córdoba, 9 de octubre de 1871, año x, núm. 2588. 
Más aún, el alza en las cotizaciones de la arroba de lanas en la plaza de Córdoba, correspondiente a los años 1869 a 1872, se nota en el crecimiento promedio calculado partiendo de 19.4 reales bolivianos a 43.6 reales de la misma moneda. ${ }^{27}$

Los mencionados problemas monetarios suscitados en 1866, precipitaron algunas quiebras de casas comerciales, posiblemente como consecuencia de mantener sus actividades sosteniéndolas con base en fuertes créditos. No hubo otra alternativa que declarar la quiebra, al no poder responder debidamente a las obligaciones financieras, decayendo en consecuencia la operatividad del tráfico que los vinculaba con los mercados portuarios afectados por la crisis. ${ }^{28}$

La crisis despertó nuevas inquietudes e incentivó proyectos inherentes a la necesaria creación de establecimientos bancarios, arguyéndose que sobre la "fuente de riqueza que producen los establecimientos de esta clase[...] como hay poco capital y no se puede hacer uso del crédito [sin bancos] que es el único que puede suplirlo, el comercio queda reducido a límites muy estrechos". 29

Todo esto sumado a las dificultades que conllevaba el sistema de coexistencia de diversos medios de pago vigente en la práctica comercial regional, que estorbaba en sus transacciones con los mercados portuarios, originó en la plaza cordobesa la aparición de casas mercantiles que lanzaron a la circulación vales o pagarés a la vista por valores de baja denominación, con la pretensión de suplir las funciones de un banco de emisión, operaciones que en definitiva nada solucionaron, por el contrario, ensombrecieron el panorama comercial al fomentar la especulación. ${ }^{30}$

En estas condiciones, al finalizar la década de 1860, las sucursales en Córdoba de los bancos comerciales de Santa Fe, Londres, Río de la Plata y Argentino, se encontraron en una clara situación de falencia al evidenciar incapacidad para absorber la moneda falsa y mantener la conversión entre la moneda circulante en el litoral y la corriente en las provincias del interior. $^{31}$

La reacción del gobierno provincial contribuyó a sembrar alarma y confusión. En efecto, declaró inaceptables los billetes emitidos por las mencionadas sucursales bancarias con la casa central establecida en otras

\footnotetext{
${ }^{27}$ Félix Converso, La lenta formación de capitales. Familias, comercio y poder en Córdoba, 1850-1880, Junta Provincial de Historia de Córdoba, Córdoba, 1993, pp. 51-52 (serie Libros, núm. 12).

${ }^{28}$ El Eco de Córdoba, Córdoba, 1 de mayo de 1866, núm. 999; 3 de noviembre de 1866, núm. 1150.

${ }^{29}$ Las Provincias, Córdoba, 27 de diciembre de 1866, año I, núm. 99.

${ }^{30}$ El Eco de Córdoba, Córdoba, 23 de agosto de 1866, núm. 1091; Las Provincias, Córdoba, 22 de agosto de 1866.

${ }_{31}$ El Eco de Córdoba, Córdoba, 2 de febrero de 1868, núm. 1493 y 13 de febrero de 1868, núm. 1502.
} 
provincias "que no ofrecen garantías a fuertes sumas o valores comprometidos y al cumplimiento de estatutos que los rige", ${ }^{32}$ agregando un inconveniente más a la circulación mercantil.

En tanto la casa financiera local, que posteriormente se convertiría en el Banco Otero y Compañía, en 1866 había lanzado una emisión de 1000 pesos bolivianos, con garantía de depósito en la Caja de Depósitos y Consignaciones, ${ }^{33}$ aunque esta entidad prestaba un respaldo débil a causa de su mala administración. Al siguiente año, el Banco Otero y Compañía emitió 10000 pesos bolivianos, ${ }^{34}$ contribuyendo a aumentar el circulante de esta moneda.

\section{LOS INCONVENIENTES ORIGINADOS POR EL USO DEL PESO PLATA BOLIVIANO}

Un informe oficial elaborado en 1872 , señaló que uno de los mayores impedimentos para el mejor desarrollo del mercado cordobés lo constituía el problema monetario, subrayando los inconvenientes que provocaba el circulante plurimonetario, que en la práctica multiplicaba los embrollos en las diversas transacciones. ${ }^{35}$

Las dificultades se experimentaron con mayor intensidad al comenzar el decenio de 1870, cuando el comercio tropezó con una pronunciada disminución en la disponibilidad de moneda boliviana. La circulación de la misma en el mercado regional interior dependía de las disposiciones del gobierno de Bolivia, que en esas circunstancias pretendía terminar la acuñación de su nueva moneda feble y se aprontaba a emitirla.

Para estos fines, se necesitaba transportar la moneda desde las provincias del norte, empresa que suponía superar la carencia de servicios de mensajería que desde Tucumán y Salta debían encargarse de distribuir el nuevo signo acuñado.

Las perturbaciones producidas en el comercio mantenido con Europa consecuentemente indujeron a los responsables de las casas exportadoras de Buenos Aires a desprenderse de fuertes sumas de dinero con destino al mercado transatlántico, y agregaron con esto un nuevo inconveniente en la fluidez de la eventual demanda de los "frutos del país", provocando determinadas retracciones en la operatoria.

La suma de estos inconvenientes abonó la incipiente sospecha acerca de la tendencia que apuntaba a una desaparición del peso boliviano. Los

\footnotetext{
${ }^{32}$ AHPC, 1869, Gobierno, t. 6, fs. 143-146; t. 7, f. 247.

${ }^{33}$ Los Principios, Córdoba, 7 de septiembre de 1866, núm. 16.

${ }^{34}$ El Eco de Córdoba, Córdoba, 9 de marzo de 1867, núm. 1252.

${ }^{35}$ "Registro de estadísticas de la república argentina", Buenos Aires, 1973, t. vi, pp. 24 y 26.
} 
bancos reaccionaron tomando recaudos para evitar la falta de instrumentos para convertir la emisión, por lo tanto, restringieron sus operaciones, provocando la acentuación de la iliquidez, cuya secuela concreta no fue otra que la limitación operativa de la plaza. ${ }^{36}$

La limitación bancaria aludida que acentuó la iliquidez fue acompanada por problemas de competitividad y de especulación, porque "a pesar que los bancos de aquí no dan dinero, los especuladores se lo proporcionan en otras plazas, con intereses más módicos y vienen a quitar el derecho a nuestros barraqueros [exportadores de lanas] que por falta de dinero franqueado por los bancos, no pueden competir con los compradores de las casas de Montevideo y de Buenos Aires". ${ }^{37}$

La falta de concreción de un acuerdo atinente a un equivalente estable y fijo para el valor de la moneda aludida agudizó las dificultades. Buscando acceder a vías de solución -aunque transitorias- el comercio de Córdoba solicitó la colaboración de su similar rosarino, con el propósito de amortiguar las perjudiciales derivaciones de la escasez de circulante que dificultaba el intercambio desde 1865.

En efecto, la carencia de convenios atinentes a equivalencias de los medios de pago se traducía en la fluctuación de los tipos de cambio, provocando pérdidas en el comercio regional: en 1865 se cambiaba a razón de 16 pesos fuertes por cada 17 pesos bolivianos. ${ }^{38}$

En tanto, la disminución eventual de las remesas de este medio de pago procedentes de las provincias interiores estimadas entre $50000 \mathrm{y}$ 60000 pesos bolivianos mensuales, agravaron la condición preocupante que aquejaba al comercio, mermado en su operatividad a causa -según determinada información de la época- de la desaparición de los denominados "medios pesos".39

La cuestión engorrosa que surgía periódicamente de la carencia de equivalencia entre las distintas monedas en relación con la boliviana prosiguió, y se observaron prácticas tales como las registradas en 1875 , año en que se concertaron operaciones con base de equivalencias acordadas entre las partes contratantes, ${ }^{40}$ que en ausencia de reglas formales echaba mano a limitaciones informales. $\mathrm{Al}$ año siguiente, desde la legislatura provincial se legisló unilateralmente para el comercio de Córdoba

${ }^{36}$ AHPC, 1870, Gobierno-Tribunales y otras oficinas, t. 3, fs. 333-334.

${ }^{37}$ El Eco de Córdoba, Córdoba, 9 de noviembre de 1871, año x, núm. 4682.

${ }^{38}$ AHPC, 1863, Hacienda, t. 692, f. 189.

${ }^{39}$ El Eco de Córdoba, Córdoba, 4 de noviembre de 1870, año Ix, núm. 2293. La solicitud efectuada al comercio rosarino consistió en que éste recibiera como medio de pago las monedas bolivianas de 400 gramos equivalente a $2 / 4$ pesos bolivianos, o sea, ocho reales y la de 500 gramos equivalente a 2.50 pesos bolivianos, igual a diez reales.

${ }^{40}$ Ibid., 11 de noviembre de 1875, año XIII, núm. 3599. 
fijando un tipo de cambio de cinco reales bolivianos a la moneda denominada "melgarejo".41 No obstante, continuaron similares inconvenientes en años posteriores. ${ }^{42}$

Las preocupaciones del sector mercantil se acrecentaron al conocer los decretos emanados del gobierno nacional en los primeros meses de los años 1877 y 1879, orientados a alterar la equivalencia oficial de la plata, en procura de morigerar las repercusiones suscitadas en Buenos Aires por las fluctuaciones del valor del metálico producidas en los mercados internacionales. La plaza cordobesa recibió con mala predisposición estas medidas, dejando trascender cierta alarma ante las consecuencias desequilibrantes en sus cuentas. ${ }^{43}$

$\mathrm{Al}$ comienzo de la década de 1880 , el tipo de cambio de la moneda boliviana, aún circulante en buena parte de las provincias del interior, sufrió depreciaciones importantes en la plaza rosarina que lograba vínculos cada vez mayores con Córdoba. En tanto, en esta plaza y en el resto de las regionales del interior, el peso boliviano aún presentaba alguna firmeza, pero cotizándose con una diferencia la devaluación que sufría en el litoral, desequilibrando en consecuencia el comercio de importación destinado hacia las provincias del centro y norte. ${ }^{44}$

Las distintas monedas corrientes, con circulante en pesos bolivianos y pesos fuertes, utilizados por igual en las provincias del interior, continuó dificultando el comercio sostenido con el litoral, donde el comercio de Córdoba compraba con cláusula de pago equivalente en oro de 16 patacones la onza. En la provincia mediterránea, desde mediados del decenio de 1870 , por la normativa legal sancionada durante 1873 , se calculaba la equivalencia 1.3121 pesos bolivianos igual a un peso fuerte, ${ }^{45} \mathrm{y}$ a partir del año 1883 un peso boliviano equivalía a 0.72 pesos moneda nacional. ${ }^{46}$ Conviene hacer la salvedad que esta equivalencia no fue observada inmediatamente de manera uniforme en toda la provincia y de acuerdo a las transacciones que se realizaban.

En lo inherente a la equivalencia relacionada con la moneda circulante en el litoral, antes mencionada, previamente a los fines de obtener-

41 AHPC, 1876, Gobierno Legislatura, t. 2, f. 32.

${ }^{42}$ El Eco de Córdoba, Córdoba, 25 de enero de 1877, año Xv, núm. 4682. Conviene recordar que en 1876 el gobierno nacional decretó la inconvertibilidad monetaria, que significó una devaluación de $30 \%$, según Roberto Cortés Conde, "Finanzas públicas, monedas y bancos (1810-1899)" en Nueva historia de la nación argentina, Academia Nacional de la Historia, Buenos Aires, 2000, t. 5, p. 491.

${ }^{43}$ El Eco de Córdoba, Córdoba, 18 de enero de 1879, año xvili, núm. 4680.

${ }^{44}$ Ibid., 1 de septiembre de 1880 , núm. 5007.

${ }^{45}$ Archivo de la Legislatura de la Provincia de Córdoba (en adelante ALPC), 1873, ActasSenado, fs. 160-167.

${ }^{46}$ Compilación de leyes y decretos[...] de la provincia de Córdoba, 1882, t. Ix, p. 325. 
la, el agente del mercado debió superar etapas y complicadas operaciones que inevitablemente se reflejaron en los precios en razón de la incidencia en los costos de la mercadería importada del extranjero.

Es por esto que el conocimiento de los tipos de cambio en épocas de fluctuaciones permanentes se transformó en un elemento de consideración ineludible y un instrumento de manejo imprescindible en cada operación mercantil. La aludida necesidad de información adecuada se explica porque la oscilación de la moneda tomada como patrón se constituyó en causa de pérdida de aquellos beneficios resultantes de operaciones mercantiles concretadas sin la prevención relacionada con las equivalencias utilizadas periódicamente.

$\mathrm{Al}$ respecto resulta apropiado reproducir el siguiente párrafo, "si tratándose de una sola moneda es difícil la apreciación exacta del costo, como ha de ser entre nosotros que tenemos diversas monedas, lo que es igual a no tener ninguna". ${ }^{47}$ En consecuencia, los conocimientos inherentes a los valores monetarios, sus oscilaciones y los costos por éstas provocados, debieron apreciarse y actualizarse periódicamente.

\section{CONFUSIONES, DESCONFIANZA Y OPORTUNISMO DEL MERCADO}

Las dificultades generales procedentes de la diversidad de moneda en uso, complicaron aún más el intercambio a partir de la Ley Nacional de $1881^{48}$ que estableció la unidad monetaria en todo el país. Las complicaciones permanecieron porque las monedas circulantes hasta la puesta en práctica de la referida disposición, continuaron utilizándose con vigencia relativa, según las zonas.

Si bien había comenzado un proceso de desvalorización de la plata debido, entre otras razones, a su desmonetización en Alemania y en

${ }^{47}$ El Eco de Córdoba, Córdoba, 8 de octubre de 1888, año XIX, núm. 5395, "Para proveerse de oro el comercio de esta plaza se provee de las del litoral, lo hace pagando por onza desde 21.25 a 22 pesos bolivianos según las estaciones y más o menos oferta de oro[...] esta enorme diferencia en el cambio y sobre todo en la frecuencia en que varía, podemos afirmar que el cálculo para la venta será tanto más difícil, puesto que esta diferencia es tan variable y tan precaria.[...] Es de tanta importancia para la venta el conocimiento de la diferencia de la moneda que un real boliviano en el precio de la onza es igual a 820 milésimos por ciento de recargo de moneda que si se hiciese el cálculos de pagar de nuestras obligaciones a oro con onzas de $6.56 \%$ pesos bolivianos, pérdida bastante por sí sola para observarse el beneficio de una venta considerable."

${ }^{48}$ La Ley de 1881 instituyó por primera vez la unidad monetaria a todo el país, tratándose del doble padrón, el peso plata de 25 gramos de plata de $9 / 000$ de fino y de 1.6159 gramos de oro. La aplicación de esta legislación produjo una ligera devaluación del peso fuerte, que tenía 27 gramos plata. Véase Roberto Cortés Conde, Finanzas, op. cit., pp. 495-496. 
otros países de doble patrón oro, en las provincias del interior argentino se comerciaba con mercados limítrofes utilizando como medio de pago moneda de plata, siendo esta práctica la sostenedora de su cotización. Aunque también políticamente sustentada por la denominada "Liga de Gobernadores" ${ }^{49}$ que pasaba por la etapa de mayor fortaleza en el contexto sociopolítico de la república.

Como consecuencia de la mencionada Ley, durante el año siguiente de 1882, en Córdoba comenzó a circular el peso moneda nacional, manteniéndose la vigencia de las monedas anteriormente referidas. Una muestra de la diversidad de signos monetarios utilizados se encuentra en la contabilidad de las recaudaciones impositivas, mientras los gravámenes nacionales se liquidaron en pesos moneda nacional, ${ }^{50}$ los provinciales se cobraron en pesos bolivianos, ${ }^{51}$ y por su parte la municipalidad de la ciudad de Córdoba los recaudó en pesos fuertes. ${ }^{52}$

La circulación del peso boliviano, aún en 1883, en Córdoba y el resto de las provincias, no pudo evitar condicionamientos especulativos porque "ni el comercio, ni los mayoristas reciben bolivianos por su valor nominal, sino con una desvalorización de $25 \%$ [...], esto ha dado margen a la especulación[...] porque hay quienes los aceptan con una desvalorización de $50 \%$ y la gente del pueblo se ha apurado a entregar a estos explotadores sus economías por la mitad de su valor". ${ }^{53}$

Con la finalidad de salvar las dificultades, se utilizaron las limitaciones informales propias de las costumbres y prácticas comerciales: "sobre equivalencias no hay ley alguna que la determine, ésta no podría tener efecto retroactivo". ${ }^{54}$

A lo largo del decenio de 1880, se sancionaron sucesivas leyes nacionales relacionadas con la moneda y su uso. A la referida de 1881 , le sucedió la refrendada en 1883 que reformó la anterior estableciendo como única moneda el peso oro, es decir, se instauró un sistema de circulación monometálico. Disponiéndose que los bancos de emisión, tanto oficiales

${ }^{49}$ Roberto Cortés Conde, Dinero, op. cit., p. 158.

${ }^{50} \mathrm{El} \mathrm{Eco} \mathrm{de} \mathrm{Córdoba,} \mathrm{Córdoba,} 29$ de enero de 1882. Los provinciales se cobraron en pesos bolivianos, Compilación de leyes y decretos[...], op. cit., p. 338.

${ }^{51}$ Compilación de leyes, acuerdos de la excelentísima cámara de justicia y demás disposiciones de carácter público dictadas en la provincia de Córdoba desde 1810 hasta 1870, Córdoba 1873, t. IX, p. 338, Córdoba, 1882.

${ }^{52}$ El Eco de Córdoba, 29 de enero de 1882, núm. 5412; La Carcajada, Córdoba, 29 de enero de 1882, año XI, núm. 552, este periódico sostuvo que esta disposición incidiría en los precios a causa de las dificultades que provocaban las equivalencias monetarias, opinión luego refrendada por $E l$ Eco de Córdoba, 28 de octubre de 1882, año Xx, núm. 5633.

${ }_{53}$ El Eco de Córdoba, Córdoba, 14 de marzo de 1883, núm. 5738.

${ }^{54}$ Esta fue la información emanada del fiscal del gobierno de la provincia de Córdoba de fecha 3 de noviembre de 1883, en AHPC, 1883, Gobierno, t. 4, fs. 17-18. 
como mixtos o particulares, sólo podrían emitir billetes pagaderos en pesos nacionales oro.

Esto significó el retiro de las emisiones anteriores, "quedando el peso plata únicamente reducido a facilitar los cambios en una proporción determinada e insignificante, lo que comporta quitar a la moneda de plata el carácter cancelatorio que la ley de 1881 acordaba". ${ }^{55}$

En Córdoba, la moneda de plata comenzó a sufrir la depreciación y la consecuente desmonetización, quedando especulativamente mercantilizada, "bien pronto algunos comerciantes hicieron de esta mercancía un objeto de exportación, ofreciendo una pequeña prima proporcional, no tardando en generalizarse esta práctica, terminando por desaparecer del mercado la moneda de plata, para dar lugar al billete de banco" ${ }^{56} \mathrm{El}$ papel moneda, no obstante la desconfianza que podía despertar entre los usuarios poco habituados a su utilización, desplazó al metálico oro.

Más tarde, la Ley de 1885 sancionó la operatoria adoptada por el uso en la generalidad de las transacciones. Es decir, declaró de curso legal los billetes emitidos por el Banco Nacional y los bancos provinciales.

Asimismo, incluyó al dinero en depósitos, extendiéndose a las antiguas cuentas realizadas en metálico, porque la reforma monetaria había reemplazado el sistema bimonetario por el referido peso oro.

$\mathrm{Si}$ bien estas medidas -en un primer momento- generaron confusión, igualmente alentaron el oportunismo. En Córdoba, se suscitaron casos litigiosos incoados contra bancos que resultan paradigmáticos y útiles para el análisis de estas situaciones.

Uno de ellos sirve para estudio de caso que informa en relación con una operación de depósito en pesos plata boliviana, concretada en el Banco Otero y Compañía durante 1870, que fue renovada periódicamente hasta 1888. Durante este largo lapso, tanto la entidad bancaria como el depositante debieron adecuarse a las medidas y cambios antes mencionados inherentes al uso monetario.

Mientras rigió la Ley de 1881, los banqueros emitieron sólo en moneda de plata, pero dos años después, debieron retirar las emisiones que no se conformaban a la nueva ley, y sin omitir medio ni sacrificio procuraron la conversión de los depósitos de plata a oro.

Los comerciantes y los particulares que en general no seguían la marcha administrativa y económica del país, al par que seducidos por la brillante perspectiva que les pintaban los banqueros para la conversión de los depósitos, veían al

${ }^{55}$ AHPC, 1910, Juzgado 2a. Comercial-capital, leg. 21, exp. 1, "la moneda nacional plata pasó a ser como cualquier otra moneda extranjera al dejar de ser nacional[...] al quitar fuerza cancelatoria a la plata".

${ }^{56}$ Ibid. 
billete de banco no sólo apreciado por el público sino por los bancos[...] todo parecía indicarles la conveniencia de lo propuesto[...], así casi todos aceptaron, y las redacciones que tenían los títulos de sus créditos fueron cambiadas por las que presentaban los bancos. ${ }^{57}$

En el caso que motivó el litigio, el mencionado depósito realizado en 1870 en pesos plata boliviana, esta moneda fue convertida en 1883, estipulándose en pesos plata nacionales. Con esta denominación se renovó sucesivamente hasta 1888, cuando el cliente del banco planteó su pago en pesos plata o en billetes de curso legal al cambio del día, mientras la contraparte aceptaba saldar la deuda pero adoptando el criterio opuesto, sosteniendo que debía hacerlo en pesos de curso legal por su valor escrito, tal como lo disponía la Ley de 14 de octubre de 1885, en su artículo tercero.

Un segundo caso litigioso contra el mismo banco, ${ }^{58}$ en el cual la suma depositada por el querellante ya había sido cumplimentada por la entidad bancaria, se interpuso una demanda pretendiendo recibir la equivalencia de la cotización que tenía en plaza el día del vencimiento. Es decir, una pretensión similar al presentado en el juicio anteriormente aludido.

Ambos casos fueron fallados en favor del banco demandado, en su desarrollo ilustran sobre los oportunismos especulativos de los individuos ante los mercados financieros, en los años en que se produjeron cambios de prácticas y de monedas.

Los alegatos aludidos resultan interesantes, porque además dejan trascender algunas creencias o apreciaciones formadas luego de la sanción de la Ley de 1883, en relación con la moneda de plata que comienza a ser considerada "como cualquier otra moneda no circulante[...] que pierde el carácter cancelatorio[...], además al billete moneda nacional oro se desestima como[...] moneda ficticia o ficta[...] y se entiende a la metálica como una moneda verdadera".

Traslucen estos argumentos y calificativos la desconfianza coyuntural respecto a la validez del papel moneda, en los comienzos de su implantación con carácter de moneda circulante:

las emisiones de moneda fiduciaria no tardaron en aumentarse particularmente las del Banco Nacional, mientras el gobierno autorizaba estas emisiones sirviéndose de ellas como recurso financiero[...] desde entonces comenzó a emigrar la moneda nacional oro[...] reemplazándola por la nominal del billete de banco[...] Comenzaron a dejarse sentir los síntomas de la crisis que luego se presenta, cuyas consecuencias trató el gobierno de atenuar con el decreto del 9 de enero de 1885 que declaró el curso forzoso del billete

57 Ibid.

${ }^{58}$ Ibid., exp. 2. 
aprobado por ley de octubre del mismo año. Tanto las variaciones monetarias, como los desajustes cambiarios y los manejos especulativos se prolongaron en el tiempo, contaminando de incertidumbre la operatoria de la plaza

Durante el segundo quinquenio de la década de 1880, las plazas del interior del país y particularmente la cordobesa experimentaron los efectos de la depreciación del papel moneda y el aumento de la cotización del oro, agravada por la restricción de los créditos bancarios. ${ }^{59}$

Los problemas emergentes de las distintas equivalencias entre moneda nacional y billetes de emisión local continuaron registrándose durante la década de 1890 , en transacciones comerciales que en ocasiones fracasaron por causa de diferencias similares a las apuntadas. ${ }^{60}$ Por caso, en el año 1891, el billete nacional cotizó $40 \%$ de premio sobre los papeles cordobeses, "el comercio y todos hacen cuestión hasta de un cuarto de centavo cuando se trata de pagar, no entregando por consiguiente moneda que tenga premio cuando pueden hacer el mismo servicio con otra que les cuesta la mitad" ${ }^{61}$

Las fluctuaciones inherentes a las mencionadas cotizaciones complicaron aún más los diversos tratos, tanto los comerciales como los surgidos de disputas judiciales. ${ }^{62}$

59 "La suba excesiva del oro tiene una influencia notable en cuanto a las operaciones de compra y venta de mercaderías, pues no hay seguridad para ningún negocio cuya base sea la importanción de artículos fabricados fuera del país que tienen que pagarse al extranjero en oro efectivo. Además los bancos restringen las operaciones de crédito hasta el punto de que hoy no sería posible que efectuaran descuentos de pagarés". El Eco de Córdoba, Córdoba, 14 de abril de 1885, año XXIII, núm. 6348; "Los compradores de fuera de plaza, con raras excepciones, demoran los pagos en razón de la escasez de sus ventas y si nuestros bancos mantienen la inacción actual, ¿de qué medios se van a valer las casas o para proveerse de los fondos que necesitan para llenar sus compromisos en el litoral o fuera del país?, los que casi siempre hay que atenderlos muy oportunamente". El Eco de Córdoba, Córdoba, 1 de abril de 1885, año XIII, núm. 6363. En 1889 el periódico El Porvenir describía los mismos problemas en los siguientes términos: "témese la gran crisis económica y comercial que viene presintiéndose[...] depreciado hasta lo más el billete inconvertible que es la única moneda circulante en el país, a consecuencia de la extraordinaria valorización del oro en relación con él, es natural que las casas introductoras busquen precaverse de desastres ulteriores, como que tienen que saldar en dicho metal sus cuentas con los fabricantes extranjeros[...] Comprando a ellos oro para vender a papel, necesitan calcular prudentemente las oscilaciones de aquel durante un periodo de cinco a seis meses, a fin de ponerse a cubierto de las eventualidades. Pero este procedimiento de poco o nada sirve como al presente sucede, el oro experimenta en breve tiempo bruscas alteraciones. En menos de un mes a recorrido el diapasón comprendido entre 175 a 215 y no gradualmente sino a saltos".

${ }^{60}$ AHPC, 1891, Gobierno, t. 8, fs. 227, 228; 1891, Juzgado 1a. Nominación Comercial, leg. 118 , exp. 5 y 17; 1892, leg. 123, exp. 12. Asimismo para las fluctuaciones en la cotización del oro véase La Libertad, Córdoba, 3 de julio de 1889, año vI, núm. 1732, y 3 de diciembre de 1898, año IX, núm. 2413.

${ }_{61}$ La República, Córdoba, 4 de noviembre de 1891, año I, núm. 68.

${ }^{62} \mathrm{Al}$ comenzar el año 1892, en "operaciones muy pequeñas" en la cotización del billete nacional había descendido a $26 \%$ el premio, en La República, Córdoba, 2 de enero de 1892, año 
Durante 1896 y 1897 se soportó nuevamente -en el mercado nacional- una etapa de depresión económica al presentar una ruptura abrupta del nivel cambiario entre metálico y papel, con las consiguientes perturbaciones en el intercambio. ${ }^{63}$

En esas circunstancias, los más audaces y perspicaces comerciantes especularon y algunos salieron ganando, pero una apreciable cantidad debió soportar perjuicios como consecuencia de las oscilaciones cambiarias. A propósito, conviene mencionar que no pocas quiebras fueron motivadas por los desniveles en la valuación del oro o el papel moneda; de acuerdo con las distintas incidencias producidas en los mercados, el impacto cambiario produjo situaciones de indefensión económica. ${ }^{64}$

\section{EL SECTOR MERCANTIL Y LAS FINANZAS}

Acertadamente, Braudel comentaba que "la tienda representa el intercambio acompañado del crédito, ya que el tendero recibe sus mercancías a crédito y las vende a crédito[...] una larga secuencia de deudas y de créditos se tiende a través del intercambio[...] una única especialización ha mostrado, en ocasiones, tendencia a manifestarse dentro de la vida mercantil: el comercio del dinero". Seguidamente advertía, "pero su éxito nunca ha sido de larga duración, como si el edificio económico no pudiese nutrir suficientemente esta punta culminante de la economía". ${ }^{65}$

Que el crédito marchó unido a la dinámica mercantil resulta un hecho evidente. Tanto aquél como el intercambio comercial, no supieron cumplir su cometido sin el acompañamiento de los medios de pago.

I, núm. 11. En tanto en el año 1895 se cotizaba a la par el peso plata boliviano igual a un peso billete nacional de curso legal, y el peso fuerte nacional plata igual a 1.50 pesos $\mathrm{m} / \mathrm{n} \mathrm{de} \mathrm{c} / \mathrm{l}$. Estos datos surgen de una disputa judicial por equivalencias del valor de los signos monetarios diversos atribuidos a los bienes sucesorios de Severo Obregón, en AHPC, 1897, Juzgado 1a. Nominación Comercial, leg. 184, exp. 2o. y Juzgado 2o. Civil Capital, leg. 22, exp. 2.

${ }^{63}$ La balanza comercial decreció abruptamente en 1896 y 1897, de 25000000 de pesos en 1895 a 4600000 pesos en 1896 y a 2900000 pesos en 1897, según Mario Rapoport y colaboradores, Historia económica, política y social argentina (1880-2000), Ediciones Macchi, Buenos Aires, 2000 , p. 89.

${ }^{64}$ AHPC, 1897, Juzgado 1a. Nominación Comercial, leg. 186, exp. 3, en autos "Fernando Torres se presenta a quiebra se consignó: sobrevino la súbita baja del oro que hasta hoy continúa y mis mercaderías compradas en diciembre de 1895 con el oro a 350 sufrieron una fuerte depreciación[...], la baja del oro causa una depreciación de más de $25 \%$ en las mercaderías compradas cuando se encontraban a 350". En los juicios por quiebras se encuentran similares argumentos: "la paralización que desde hace meses sufre el comercio, las fluctuaciones del oro tan rápidas como estruendosas, [...] han venido a conmover profundamente el desarrollo del comercio despertando desconfianzas", en AHPC, 1896, Juzgado 1a. Nominación Comercial, leg. 172, exp. 9.

${ }^{65}$ Fernand Braudel, La dinámica del capitalismo, Alianza Editorial, Madrid, 1985, pp. 30 y 73. 
Por otra parte, conviene tener presente que "El capital usurario adelanta, en forma de dinero, materias primas e instrumentos de trabajo a los productores directos, a los que explota merced a altos intereses. Esa explotación es una forma[...] de convertir su dinero en capital." 66

Algunos de estos planteos encuentran similitudes en ciertos acontecimientos que ocupan la atención de la temática en estudio.

\section{LAS CONCEPTUALIZACIONES INHERENTES AL FINANCIAMIENTO}

Interesa detener el análisis en la ideas concebidas respecto al crédito entre los particulares y peculiarmente al financiamiento de la operatoria mercantil.

Un informe fechado en 1856, elaborado por comerciantes, resulta ilustrativo y útil para conocer la temática en cuestión. Considerado sumamente rico y valioso su testimonio, no puede eludirse la transcripción de algunos párrafos que exponen los problemas financieros vigentes no sólo en los años en que se plasmó, sino que cobra importancia para los lapsos anteriores y posteriores a la década de 1850 .

Los redactores del documento, allegados al comercio y conocedores de sus problemas, explicaron las cuestiones relacionadas con los aspectos financieros en los siguientes términos:

el comerciante que sufre una estagnación en su capital cuyo oficio es circular, tiene que buscar otro para suplirlo, a fin de no parar o disminuir el giro de su comercio, por lo tanto, lo toma a premio, pero como el numerario en circulación al servicio del comercio no se aumenta por iguales causas, siendo la procura mayor que las ofertas, el resultado es que el dinero aumenta de valor y el prestador exige por el mayor premio. Si para obtener la cantidad necesaria, ocurre el comerciante a sus corresponsales de otra plaza, dando letras de cambio, como no aumenta con esta operación el dinero en circulación, porque el valor de la letra apenas muda de las manos del tomador para las del girador, claro está que la libra vale tanto menos cuanto más vale el dinero que por ella se da, y el comercio sufre el perjuicio de un cambio desfavorable. A más, el corresponsal que suple los fondos cobra por ellos cuando menos el rédito de su plaza y como el capital obtenido así no es empleado en reproducción, sino en suplir la falta que en la circulación dejó el capital paralizado todo el importe de los réditos pagos al prestador extraño disminuye en igual cantidad la masa de dinero de la provincia[...] La misión del comerciante es facilitar el cambio de los productos, por este servicio recibe del consumidor y del productor un interés, y por esto adiciona al costo de la mercadería que compró para introducir todos

${ }^{66}$ José Carlos Chiaramonte, Formas de sociedad y economía en Hispanoamérica, Editorial Grijalbo, México, 1983, p. 181. 
los gastos con ella hechos y la utilidad hasta el momento de venderla al consumidor que es el que efectivamente paga todo. ${ }^{67}$

Este interesante documento refiere la necesidad de financiación de la circulación mercantil, la escasez de dinero disponible para el crédito, cuya secuela es el encarecimiento del capital a préstamo y la práctica consuetudinaria consistente en la transferencia de los costos y utilidades a los precios que inevitablemente deberá asumir el consumidor.

Reitera que la toma de capitales a préstamo, frecuentemente se constituyó en el resultado de una necesidad práctica del intercambio. Porque a los fines de afrontar los gastos peculiares a la circulación tuvo que "ocurrir y recibir la ley de los capitalistas que les franquearon fondos con muy onerosas condiciones". ${ }^{68}$

Los testimonios producidos al promediar la década de 1850, expresan implícitamente una marcada conceptualización mercantil del crédito, sosteniéndose públicamente, "el dinero es una mercancía y el poseedor de ella debe ser libre para disponer a su voluntad" (la tasa de interés). ${ }^{69}$ Las ideas especulativas que llevarán al progresivo encarecimiento del dinero, quedaron anotadas sin cortapisas en estos sueltos periodísticos.

Conceptos similares anotaba Mariano Fragueiro, figura estrechamente vinculada al ámbito mercantil: "Todos los valores que concurren al mercado pueden dividirse en tres clases: mercancías, documentos de crédito y moneda[...] a las dos primeras llamaré efectos[...] son artículos de comercio." 70 De este modo, el crédito quedó presentado como un instrumento mercantilizable.

El mismo autor consideró que "No se da dinero a interés por simpatías ni por beneficencia, se da por negocio, para hacer una ganancia sobre la seguridad de los valores que posee el deudor."71

Estos conceptos se presentan como asumidos y difundidos en los distintos sectores sociales, tal como se constata en las opiniones publicadas en la época, tales como "el interés [del dinero] no importa otra cosa que el alquiler de un capital prestado por uno y recibido por otro". En procura de reafirmar este juicio se sostuvo "este capital hubiera podido ser empleado por su dueño en otros objetos capaces de redituar o producir

${ }^{67}$ El Imparcial, Córdoba, 7 de agosto de 1856, año II, núm. 155.

${ }^{68}$ AHPC, 1856, Gobierno, caja 243, carp. 4, f. 405.

${ }^{69}$ El Imparcial, Córdoba, 12 de diciembre de 1855, año I, núm. 44.

${ }^{70}$ Mariano Fragueiro, Cuestiones argentinas y organización del crédito, estudio preliminar de Gregorio Weimberg, Numismática y Ciencias Históricas, Buenos Aires, 1976, pp. 308-309.

${ }_{71}$ Ibid., p. 232. El autor se presenta como un acérrimo enemigo del crédito privado y defensor del público, "No pretendemos abolir el interés del dinero[...] se desea solamente corregir los abusos de la usura." 
provechos. El interés es el equivalente de estos provechos que habilita a lucrar al que toma el dinero". ${ }^{72}$

\section{LA TENDENCIA ESPECULATIVA DE LA OPERATORIA CREDITICIA}

$\mathrm{Al}$ promediar la década de 1850 , se consideró inaceptable la tasa de $6 \%$ anual aplicada sobre el capital prestado. La misma procedía de una antigua práctica en el comercio que puede considerarse imbuida de peculiares características convencionales y operativamente consuetudinaria. Esta tasa en el decenio de 1840 había caído en desuso, siendo la real más elevada.

El estilo financiero paulatinamente se quebró, ante consideraciones compartidas como las oportunamente anotadas, del siguiente tenor "el dinero[...] no puede tener un precio fijo, fluctúa de acuerdo con la abundancia o escasez de capitales, el tiempo del préstamo, el interés". ${ }^{73}$

Las tergiversación de las limitaciones informales y las disposiciones concernientes a contener la usura fue evidente en tal magnitud, que la legislatura cordobesa decidió tomar cartas en el asunto, abocándose a la discusión de un proyecto de ley propiciatorio de prácticas convencionales elaboradas entre las partes, a fin de fijar la tasa de interés a aplicar en las operaciones créditicias.

No obstante, en la ley sancionada poco después explícitamente se asumió el crecimiento de las tasas aplicadas en la plaza, al reconocer que "cuando no se hubiese estipulado un interés fijo, deberá éste calcularse a razón de $10 \%$ anual". ${ }^{74}$

La labor legislativa trató de vindicar los hábitos anteriormente practicados, ante las operatorias cada vez más frecuentes que provocaban el alza de las tasas, porque

las leyes son eludidas fácilmente y con daño del deudor. Entre nosotros se ve frecuentemente que encontrando el dueño del capital una traba poderosa en la ley para colocar dinero a un interés igual al corriente de plaza, se ve forzado a eludir las trabas de aquella, bien expresando en el contrato un capital fingido o reteniendo en manos del prestamista, un excedente de interés o finalmente capitalizando en el vale o letra el interés o el dinero recibido, condiciones que

${ }^{72}$ El Imparcial, Córdoba, 12 de diciembre de 1855, año I, núm. 44.

${ }^{73}$ Ibid.

${ }^{74} \mathrm{Ibid}$., 5 de julio de 1857, año III, núm. 389. El proyecto presentado por los representantes de extracción mercantil García, Peñaloza y Casas, en otros dos artículos estipulaba: 1) el interés del dinero dado a apremio, será en adelante convencional entre las partes. 2) quedan derogadas todas las leyes que fijen un interés preciso al dinero. La Ley fue sancionada con fecha 4 de agosto de 1857, véase AHPC, 1856-1857, Leyes y decretos, t. 8, f. 182. 
son aceptadas o aún fomentadas por el deudor, que de otra suerte no obtendrîa el dinero. ${ }^{75}$

Las limitaciones formales sancionadas no se cumplían a sabiendas de las partes, mediante procedimientos espurios en los que se anotaban sumas superiores a las realmente prestadas, descontando los intereses por adelantado o capitalizándolos. "Las sumas que se dan a interés no son iguales al capital monetario, son excesivamente mayores porque están regiradas. El uno recibe dinero al nueve y lo pasa al otro al doce, éste sigue el negocio al quince, y de aquí pasa al 18, al 24 y quién sabe a cuanto más. De modo que un mismo capital figura en diferentes deudas." ${ }^{\prime \prime 6}$

$\mathrm{Al}$ revisar los registros notariales, hasta los últimos años de la década, más precisamente hasta 1858 , puede comprobarse la consignación de tasas de interés -en operaciones realizadas entre particulares- que no superaban $6 \%$ anual, ${ }^{77}$ confirmando la anotación falseada del acuerdo previo entre partes que refieren los testimonios mencionados. De hecho, a partir de la sanción de la Ley antes aludida, comienza a observarse una gradual alza que como antes se refirió alcanzó en las décadas posteriores a duplicar y triplicar la tasa.

Sin duda, las prácticas financieras variaron comparativamente a aquellas operadas medio siglo antes, y las tasas de interés crecieron conforme la circulación mercantil se amplió y el dinero se encareció. Al respecto, cabe considerar con qué nostalgia recordaban los viejos comerciantes las habilitaciones que en Córdoba se operaron en la década de 1820. Las mismas consistían en acuerdo financieros, a resultas de que se entregaba mercancía al comanditario, quien las vendía a cambio de una comisión previamente convenida que oscilaba alrededor de $4 \%$ o una parte de las utilidades, cuando el habilitado asumía los gastos. ${ }^{78}$

Se trataba de un préstamo generalmente en especie que los más importantes comerciantes otorgaban a pequeños comerciantes ambulantes, que al empeñar sus pocas pertenencias, garantizaban una venta exclusiva al comerciante citadino. El circuito entre ciudad y campaña, es decir, el contacto que vinculó al comerciante -tendero establecido en la plaza mercantil con el consumidor rural- se cumplía a través de los aludidos mercaderes ambulantes que periódicamente realizaron dicho giro.

${ }^{75}$ El Imparcial Córdoba, 12 de diciembre de 1855, núm. 44.

${ }^{76}$ Fragueiro, Cuestiones, op. cit., p. 236.

${ }_{77}^{74}$ AHC, Protocolo de escribanos, registro 1, t. 190, 192, 193 y 194; registro 2, t. 13 y 15 .

${ }^{78}$ Ibid., 1827-1828, registro 2, fs. 11-12, 40-41; 1834-1838, Juzgado de Comercio, leg. 3 , exp. 8; 1851-1855, Protocolo de escribanos, registro 1, t. 132, f. 59. 
No siempre esta forma del crédito resultaba barata, más adelante en el tiempo la variante tomaba la conformación participativa por mitades o un tercio de las utilidades, asumiendo los gastos el habilitado. ${ }^{79}$ Esto implicaba un sobreprecio que llegaba hasta $12 \%$ como máximo, cuando los precios de las mercancías ultramarinas se elevaban coyunturalmente. ${ }^{80}$

Esta digresión cronológica sirve para marcar una etapa, que podría denominarse periodo prebancario en el crecimiento de las tasas de interés aplicadas al crédito, que al aproximarse el medio siglo se pactaban con cláusulas hipotecarias, siendo las propiedades urbanas las garantías más frecuentes, posiblemente a causa del menor valor comparativo con que se apreciaban los bienes raíces rurales.

Conviene acotar que tanto durante la primera mitad del siglo XIX como en la segunda, una de las razones con que el sector mercantil justificaba la práctica de la acumulación en bienes inmobiliarios de la ciudad capital, se fundaba en su utilización como respaldo financiero. ${ }^{81}$

La relación de dependencia financiera del comercio minorista con respecto al mayorista, cubre otro aspecto de la operatoria financiera habilitadora con diversa organización, práctica que se continuará en el siglo Xx. "Las relaciones entre los comerciantes por mayor y los de menudeo son prácticamente, aunque sin estipulación, una sociedad de habilitación o de comandita en la que el comprador tomará a interés del otro". ${ }^{82}$

Resultan numerosas las operaciones de este género protocolizadas por-comerciantes. En ocasiones las secuelas fueron perjudiciales para quienes comprometieron la cláusula de remate o mediante apurados acuerdos sólo convenientes al prestamista, no faltaban las pactadas en condiciones de amortización, como consecuencia de éstas se comprometía la producción del acreedor como medio de pago. ${ }^{83}$

A los préstamos habilitadores se los encuentra más adelante en el tiempo, con otras características. Avanzada la década de 1870 la firma cordobesa Ferreyra y Compañía financió emprendimientos azucareros en la provincia de Tucumán. Específicamente estas inversiones financieras fueron destinadas a la posterior comercialización del azúcar y el alco-

${ }^{79}$ Ibid., 1820-1826, Protocolo de escribanos, registro 3, fs. $361-364$; 1835, registro 3, leg. 129 , exp. 6.

80 Ibid., 1825-1831, Juzgado de Comercio, leg. 1, exp. 6.

${ }^{81}$ Converso, Relaciones, op. cit.; La lenta formación, op. cit.

${ }^{82}$ Fragueiro, Cuestiones, op. cit., p. 235.

${ }^{83}$ AHPC, Protocolo de escribanos, registro 1, t. 195-196, 199-200, 225; registro 2, tt. 24 y 28; registro 3 , tt. 20 y $28 ; 1869$, registro 1, t. 201, f. 112. Por este último documento se registró el préstamo de 700 pesos bolivianos de Julian Amenabar a Juan Pereyra de Cruz del Eje, éste se comprometió a amortizar a los seis meses con cien arrobas de lana y 50 fanegas de trigo. 
hol elaborados en los ingenios tucumanos, por lo tanto, el crédito se otorgaba con el propósito de concentrar una importante cantidad del producto a un precio fijo generalmente por debajo del cotizado en el mercado. El productor habilitado obtenía así el capital variable que necesitaba, pero a cambio se comprometía a vender toda la cosecha de azúcar y aguardiente al habilitador, además de pagar una tasa de interés de $12 \%$ anual. $^{84}$

Estas operaciones crediticias transcendieron los límites provinciales y se orientaron a emprendimientos productivos, pero con una implicancia posterior en la comercialización de la cosecha financiada.

Un par de decenios después, Vicente Castro, agente del comercio de Córdoba, concretó acuerdos crediticios habilitadores similares durante los últimos decenios del siglo XIX, los que fueron mantenidos o renovados hasta la primera década de la siguiente centuria.

Sus contratos consistieron en habilitar con fuertes sumas de dinero la producción y posterior compra de importantes partidas de azúcar, cuando se encontraba en plena etapa de elaboración, recibía las garantías hipotecarias hasta que se efectuara la entrega de la mercadería. Además de un reconocimiento de comisiones calculadas sobre el resultado de las ventas y las seguridades en la adjudicación exclusiva de la consignación del producto, no sólo para Córdoba, sino para las provincias de San Juan, Mendoza y San Luis. ${ }^{85}$

Estas operaciones comparten rasgos comunes, tales como los financistas-habilitadores que fueron casas comerciales establecidas en Córdoba, y las cláusulas similares presentan operaciones con las características prebancarias aludidas, con significancia interprovincial.

\section{LA OPERATORIA FINANCIERA \\ DURANTE LA TRANSICIÓN PREBANCARIA A BANCARIA}

El sector mercantil reconoce una constante vinculación con estas operaciones en función de prestamista o como tomador de dinero a premio para utilizarlo en la financiación de la circulación peculiar al intercambio. Se constituyó en actor de las dos funciones o aspectos aludidos,

${ }^{84}$ José Antonio Sánchez Román, "Las finanzas prebancarias en Tucumán en un momento de transición económica: 1850-1876", ponencia considerada en las VII Jornadas Interescuelas, Neuquén, 1999.

${ }^{85}$ Contrato con Berho y Padilla, habilitó a cuenta 60000 pesos, AHPC, 1898, registro 25. Contrato con Guzmán y Cía., adelantó a cuenta 140000 pesos por 1000000 de kilogramos de azúcar y otro 1000000 de litros de alcoholes sin especificar. AHPC, 1901, registro 3, inventario 148 , fs. $864-872$. 
dependiendo siempre de las posibilidades de conseguir los beneficios excedentarios necesarios en sus actividades específicas o en los casos que presentaban las carencias de capital líquido para destinar en éstas.

Con frecuencia se encuentran agentes del comercio en las escrituras protocolizadas, tanto como acreedores o deudores; pero fueron contados aquellos que soslayando sus actividades compartieron con éstas la propia de las finanzas, menos aún fue el número de los que al abandonar su oficio mercantil se dedicaron exclusivamente al manejo financiero.

De estos últimos es rescatable lo realizado por Benjamín Otero, quien en 1864 disolvió la sociedad mercanti1 ${ }^{86}$ en la que regenteaba un almacén mayorista, y en poco tiempo comenzó sus primeras experiencias financieras en función de prestamista y luego emitiendo billetes de baja denominación.

En el año 1870, el comercio instalado en Córdoba contabilizaba préstamos tomados del -en esa época formalmente constituido- Banco Otero y Compañía, por las sumas de 64064.04 pesos fuertes, equivalentes a 16 onzas oro y de 499842 pesos bolivianos, equivalente a 21 onzas oro. ${ }^{87}$ Estos créditos cuyo otorgamiento comenzó desde años anteriores, presentan un monto total significativo de la dinámica impuesta a la operatoria financiera.

Otro agente del comercio, Rafael Torres, organizó un establecimiento algo similar que denominó Caja de Préstamos y Ahorros, ${ }^{88}$ casa financiera que aunque no llegó a constituirse en banco, utilizó el capital procedente de la previa actividad mercantil en función de capital financiero, multiplicándolo mediante operaciones usurarias realizadas durante los años 1869 hasta 1874.

Esta casa de préstamos operaba en general con montos prestables que no alcanzaron valores altos, los colocaba aplicando tasas de interés que sigilosamente no se protocolizaban, pero que documentaba las cláusulas hipotecarias, utilizaba éstas en diversas oportunidades para llevar a cabo su ejecución, se apropió de los inmuebles propiedad de tomadores del dinero a premio que no pudieron cumplir con sus deudas. ${ }^{89}$

El financista mencionado otorgaba créditos hipotecarios y capitalizaba acumulativamente las tasas de interés, administrando un sistema

${ }^{86}$ El Eco de Córdoba, Córdoba, 3 de junio de 1864, núm. 439. Disolución de la sociedad Benjamín M. Otero y Cía.

${ }_{87}$ "Registro de estadísticas de la República Argentina", Buenos Aires, 1971, t. vI, pp. 24-27.

${ }^{88}$ AHPC, 1864, Gobierno Legislatura, t. 1, f. 303.

${ }^{89}$ Ibid., 1872 , registro 2 , t. 27 , f. 580 ; t. 32 , f. $1279,1869$. 
usurario. En los cinco años mencionados se protocolizaron 76 escrituras de préstamos hipotecarios, en su mayoría con las características descritas. $^{90}$

El establecimiento de Torres contabilizó durante los años referidos un monto total prestado sobre hipotecas de bienes raíces de 107272 pesos bolivianos. Las operaciones se realizaron partiendo de un capital inicial declarado de 30041 pesos bolivianos, de este sólo llegó a contar en efectivo la cantidad de 4941.77 pesos bolivianos, el resto se contabilizaba en bienes inmuebles y documentos, alcanzando a evolucionar un capital en giro calculado en 7815498.75 pesos bolivianos. El notable crecimiento del capital, realizado entre 1869 y 1874, muestra la envergadura usuraria y fronteriza con el delito de sus negocios financieros.

Una distinta operatoria se fundaba en la aceptación de dinero en depósito. Una vez realizado éste, de acuerdo con los montos, la entidad prometía reconocer unas tasas de interés que oscilaron entre 15 y $18 \%$ anual y para los montos que ingresaban a una caja de ahorros que había implantado, asignaba un $12 \%$ anual. ${ }^{11}$ Considerando las tasas que pagaba, no resulta difícil suponer la magnitud de las que aplicaba a sus préstamos.

Dos años después, en 1876, al ventilarse la quiebra de la Casa Torres, calificada como fraudulenta, el responsable atribuyó la misma a la crisis monetaria por la que la plaza atravesaba, agravada por las consecuencias de los hechos político-bélicos convulsionantes producidos en 1874, arguyendo que estas fueron las causales que imposibilitaron a sus deudores de amortizarla en el tiempo convenido. Estos argumentos son reales, ${ }^{92}$ pero debe agregarse además la deficiente administración que trasuntan los documentos judiciales y las evidentemente usurarias tasas de interés asignadas que en definitiva tornaron incobrables las deudas.

Otras operaciones poco claras imbricadas en la operatoria financiera, le permitieron a la Casa Torres reunir en propiedad 22 inmuebles, cuya

${ }^{90}$ Ibid., Protocolo de escribanos, registro 1, t. 202; registro 2, t. 24-26, 28-31, 34-37; registro 3 , t. 37,39 ; registro 4 , t. 26 . En algunos pocos casos se consignan deudas por interés capitalizados semestralmente que llegan a porcentajes por demás exagerados e imposibles de cumplir, en uno de $160 \%$ anual y en otro $358 \%$ anual. Se detectaron en las escrituras: en 1869 dos préstamos por un total de 2624 pesos bolivianos, en 1871: 32 préstamos por un total de 12688 pesos bolivianos, en 1872: 17 préstamos por un total de 7062 pesos bolivianos, en 1875: 20 préstamos por un total de 9805 pesos bolivianos y en 1874: cinco préstamos por un total de 3375 pesos bolivianos.

${ }_{91}$ AHPC, 1876, Juzgado de Comercio, leg. 46, t. 1, exp. 1-2, t. 2, exp. 7, 12-13.

${ }^{92}$ Ibid., debe considerarse que el total de descuentos y prêstamos de la casa sumaron 241738.89 pesos bolivianos, de éstos se amortizaron sólo 172126.52 pesos bolivianos. Además, los préstamos prendarios alcanzaron 60947.56 pesos bolivianos y fueron amortizados 53203 de igual moneda. 
valuación total ascendía, en 1875, a la suma de 43148.50 pesos bolivianos, que se aproximaba a la duplicación del monto inicial valuado en inmuebles cuando pocos años antes había iniciado las operaciones.

Durante la década de 1870, la capitalización de las tasas de interés, incorporando los intereses registrados -en estado de morosidad por falta de pago- al capital prestado, pactadas entre particulares, se presenta con cierta frecuencia, pautando una práctica financiera aceptada en la plaza. ${ }^{93}$

Evidentemente esto desataba un efecto de encarecimiento del dinero financiero, y reducía las posibilidades de inversión comercial o productiva, agravando más aún la situación de los pequeños comercios por la falta de fluidez monetaria antes aludida.

\section{El CRÉDITO DEL COMERCIO TOMADO POR EL ESTADO}

Un distinto aspecto de la operatoria crediticia lo constituye el inherente a los préstamos de particulares tomados por el Estado provincial. Operaciones generalmente vinculantes con agentes mercantiles, en su calidad de prestamistas. Durante la mayor parte de la primera mitad del siglo XIX se registraron de diverso carácter -forzosos algunos, voluntarios otros-, siempre involucrando al sector que por su particular actividad contaba con capitales líquidos. Algunas de estas financiaciones al Estado resultaron inconvenientes al comerciante a causa de la falta de cumplimiento por parte del tomador del crédito. ${ }^{94}$

A partir de 1853, encontramos un elemento distintivo inherente a las cláusulas pactadas referentes a las tasas de interés ofrecidas por el Estado y luego reconocida por la administración fiscal con aprobación del aparato político burocrático de la provincia. ${ }^{95}$ Es decir, se contemplaba una posibilidad cierta de reembolso.

Dos años después, la siguiente operación crediticia acordada con el Estado contiene otro componente distintivo en comparación con la anterior. Es el inherente a las tasas de interés anual que en esta oportunidad

\footnotetext{
${ }^{93}$ AHPC, Protocolo de escribanos, registro 2, t. 33, f. 1805; t. 35, f. 750; 1876, Juzgado de Comercio, leg. 46, exp. 1.

${ }^{94}$ Félix Converso, "Los recursos fiscales y financieros del Estado, tomados al comercio regional" en Finanzas públicas y mercado de mercancías en el siglo XIX, Centro de Estudios Históricos, Córdoba, 1995 (Colección Cuadernos, núms. 13-14); "Las finanzas públicas y el comercio de Córdoba, 1836-1855", Revista de Economia, Banco de la Provincia de Córdoba, núm. 67, 1992, Córdoba; “¿Los créditos compulsivos deterioraron económicamente a los mercaderes españoles? Nueva información para el caso Córdoba (1806-1830)", Anuario de Estudios Americanos, t. L, núm. 2, 1993, Sevilla.

${ }^{95}$ AHPC, 1853, Hacienda, t. 616, comp. 274. Préstamo por un total de 10575 pesos bolivianos a una tasa de interés anual de 6 por ciento.
} 
se pactaron duplicando el premio, es decir, de 6\% anterior se pasó a $12 \% .{ }^{96} \mathrm{~A}$ mediados de la década de 1850 , el gobierno se puso a tono respecto de las tasas de interés pactadas entre particulares, contratando a un premio no menor a $12 \%$, simplemente porque no conseguía buena disposición para financiar dinero más barato.

Superado el decenio de los años cincuenta, nuevamente la administración provincial accedió a buscar la paridad o por lo menos la aproximación al nivel de tasas acordadas en el mercado financiero local, reconociendo en $186118 \%$ anual en un préstamo por un monto de 11500 pesos. ${ }^{97}$

Sólo el transcurso de pocos meses fueron necesarios para que el Estado urgido por la falencia fiscal, asumiera las elevadas tasas de interés aplicadas en la plaza, al aceptar dinero a un premio de $24 \%$ anual; ${ }^{98}$ manteniendo la aceptación de estas condiciones durante la década de 1860 y reconociendo tasas de interés anuales oscilantes entre 18 y 24 por ciento. ${ }^{99}$

La coexistencia de diversos medios de pago antes referida, la falta de circulante en la plaza, particularmente la moneda de oro, las dificultades producidas en el tránsito mercantil a causa de las deficiencias en los caminos y en los medios utilizados, fueron factores incidentes en el encarecimiento del dinero financiado, ${ }^{100} \mathrm{y}$ en el cambio de la operatoria en el sistema.

A estos condicionantes debe agregarse otros, al tratar las operaciones financieras pactadas con el Estado que incidieron en la elevación de las tasas. Como antes se mencionó, la falta de cumplimiento de las deudas crediticias del Estado cambió las cláusulas en los convenios; el tomador debió aceptar recortes en los plazos y tasas crecientes. En 1858 se legisló en lo inherente a la consolidación de deuda pública contraída desde 1854 hasta 1856, que comprendía entre otra a los "intereses atrasados de empréstitos y depósitos". ${ }^{101}$ De acuerdo con lo dispuesto, las tasas convenidas con los prestamistas debían actualizarse, hasta la fecha de liquidación, en 10 por ciento.

Posteriormente, durante 1862 , se sancionó la consolidación de las deudas comprometidas desde 1858, con excepción de los empréstitos y

${ }^{96}$ Ibid., 1855, Hacienda, t. 636, comp. 222.

${ }^{97} \mathrm{Ibid}$., 1861, Hacienda, t. 671, comp. 30 . Ocho firmas comerciales de la plaza financiaron esta operación.

${ }_{98}$ Ibid., Gobierno, t. 1, f. 73. f. 457 .

${ }^{99}$ AHPC, 1862, Hacienda, t. 676 , comp. $195 ; 1866$, t. 714,1867 , t. $718 ; 1866$, Gobierno, t. 2 ,

${ }^{100}$ Ibid., 1866, Hacienda, t. 712, f. 904; Gobierno, t. 2, f. 457.

${ }^{101}$ Compilación de leyes y decretos[...] de la provincia de Córdoba, 1873, t. II, p. 141. 
los intereses devengados. En consecuencia, la incredulidad y la falta de confianza se hizo público, "Quien cree en el valor de la deuda consolidada por un gobierno cuyo crédito no tiene base y que va dejando de periodo en periodo en pos de una muchedumbre de acreedores defraudados". ${ }^{102}$ En coincidencia los prestamistas obligaron al Estado acreedor a asumir las crecientes tasas de interés antes aludidas. Otro aspecto del asunto es la evidencia de que la peculiar deuda pública influyó, por su propia incidencia, en el tratamiento del costo de la financiación, al acordarse la actualización de tasas según las fechas de amortización efectiva.

\section{LA ETAPA BANCARIA, EN LA CIUDAD CAPITAL}

En los comienzos de la etapa bancaria -que en la ciudad puede situarse en la década de 1870 - las denominadas "casas de préstamos" cobraron entidad y suficiente despliegue financiero, ante una operatoria crediticia bancaria restringida como más adelante se referirá.

Algunos excesos se practicaron en la siguiente década, pueden observarse en operaciones crediticias con garantías hipotecarias sobre inmuebles, pero pactadas además con cláusula que obligaba al tomador a un pago de alquiler sobre la casa gravada -sin duda de su propiedad, aunque inmovilizada por la hipoteca- durante el lapso en que se otorgaba el préstamo. ${ }^{103}$ Es decir, soportaba las tasas de interés a las que se sumaba un falso canon, incorrecta y subrepticiamente aplicado.

Excesos como estos fueron denunciados a fines del siglo XIX, adjetivándolos como "abusos de casas de préstamos y empeños de la categoría de usurarios[...] con intereses tan subidos que rayan lo escandaloso e inmoral", ${ }^{104}$ con tasas que alcanzaron $24 \%$ mensual en 1899 , en una coyuntura de merma de disponibilidad del capital líquido en la plaza. ${ }^{105}$

Comparativamente los intereses aplicados habían disminuido en los años próximos posteriores a 1895 , con referencia a los pactados dos decenios antes, no obstante al culminar el siglo nuevamente fueron considerados abusivos, porque en la financiación para la compra y venta de mercancías, la tasa usual rondaba el $12 \%$ anual, con cláusula de garantía hipotecaria. ${ }^{106}$ Pero una vez ocurrida la crisis de 1890 comenzó a dificultarse

${ }^{102}$ El Eco Libre, Córdoba, 27 de agosto de 1862, 2a. época, año III, núm. 314.

${ }^{103}$ La Libertad, Córdoba, 8 de marzo de 1894.

104 Ibid., 4 de abril 1899, núm. 2508.

${ }^{105}$ Ibid., 13 de mayo 1898, núm. 2247.

${ }^{106}$ AHPC, 1891, Juzgado 1a. Comercial, leg. 121, exp. 30 y 37; 1899, Juzgado 2a. Comercial, leg. 3 , exp. 4 . 
el cobro de estas deudas y las cancelaciones de fiados concedidos, ${ }^{107}$ en consecuencia crecieron las tasas, llegando a oscilar entre 15 y $18 \%,{ }^{108} \sin$ omitir los excesos mencionados anteriormente.

La operatoria del segmento del comercio dedicado a la importación de mercancía extranjera, se prestó con mayor frecuencia -por falta de financiación genuina- al crédito abusivo, que le permitía conseguir algunas facilidades dispensadas a la proveeduría de mercancía en el largo plazo. ${ }^{109}$

A estas operaciones se agregaron otras, como el descuento de documentos extendidos a nombre de casas de Buenos Aires o Rosario y la aceptación de depósitos por parte de terceros pactados con intereses anuales. ${ }^{110}$ Asimismo, se acostumbró entre casas de comercio importantes, convenir la apertura de créditos por un monto determinado con garantía hipotecaria e intereses anuales acordes a los vigentes en la plaza. ${ }^{11}$

Un número reducido de fuertes comerciantes prestaban pequeñas sumas de dinero en operaciones pactadas con cláusula de garantía hipotecaria. Estos créditos se protocolizaron con alguna frecuencia, afectando a distintos deudores.

En algunas oportunidades agregaba una condición referida a la cancelación de intereses por trimestres anticipados, en tanto otros otorgaban préstamos por sumas elevadas. No siempre estos créditos se pactaron a $1 \%$ mensual o menos, hubo convenios peculiares registrados en tasas de interés oscilantes entre 15 y $18 \%$ anual, en las décadas de 1880 y $1890 .{ }^{112}$ Como resultado de las deudas, los prestamistas mencionados trababan embargos y tomaban posesión en propiedad de los inmuebles afectados hipotecariamente. ${ }^{113}$

Esto acontecía en la ciudad de Córdoba, donde los créditos otorgados por el banco oficial, es decir, el Banco Provincial de Córdoba seguían una política financiera restringida y por demás sectorizada. En el decenio de 1880, funcionarios del banco aseveraban que "El crédito en cuenta corriente se acuerda únicamente a quienes tienen negocio establecido", 114 es decir, los préstamos se otorgaban a un determinado seg-

${ }^{107}$ Ibid., 1901, Juzgado 2a. Comercial. leg. 6, exp. 1.

${ }^{108}$ Ibid., leg. 1, exp. 14; 1903, Juzgado 1a. Comercial, leg. 3, exp. 2.

${ }^{109}$ Los Principios, Córdoba, 23 de enero de 1903, núm. 2552.

${ }^{110}$ Puede citarse operando de este modo a Rogelio Martínez, en Instituto de Estudios Americanistas, Fondo Documental, documento núm. 12 816, AHPC, 1905, Juzgado 2a. Comercial, leg. 3, exp. 17.

${ }^{111}$ Heriberto Martínez fue uno de los comerciantes que más frecuentemente utilizó esta operatoria, AHPC, 1900, registro 3, t. 143, fs. 125, 717, 832. Reschia y Cía., AHPC, 1903, registro 23, t. 9, David y Antenor Carreras, AHPC, 1894, Juzgado 1a. Comercial, leg. 14, exp. 6.

${ }_{112}$ AHPC, Notariales, registro 1, años 1885-1896, registro 3, 1890-1899; registro 23, 1897.

${ }^{13}$ Ibid., Juzgado 1a. Nominación Comercial, 188, leg. 106, exp. 14; 1895, leg. 12, exp. 7.

114 Nota del banco provincial en respuesta a un solicitante de un crédito en 1886, transcrita por M. C. Boixados, "El financiamiento de la expansión urbana a través de la documentación 
mento del comercio con algún respaldo en activos, capital líquido y giro propio. La cartera crediticia del banco tendía a favorecer a un grupo mercantil en detrimento de la actividad productiva. ${ }^{115}$

\section{EN EL INTERIOR PROVINCIAL}

La etapa de servicio bancario comenzó en el interior de la provincia, con alguna demora recién en el siglo $\mathrm{xx}$, esta carencia de atención bancaria en las plazas rurales obligaba a la difícil tramitación en la capital o la recurrencia al prestamista local, con frecuencia asumían esta función los propietarios de casas de ramos generales.

Con asiduidad y ante la carencia de un conveniente crédito bancario o por ausencia de estas instituciones -como acontecía en la mayor parte del interior provincial- quienes hacían las veces reemplazando al servicio financiero, fueron precisamente comerciantes, algunos sólidamente establecidos en su actividad y con reconocido respaldo económico dentro del espacio en que desarrollaban su actividad.

Los comerciantes instalados en la campaña agrícola dependían tanto como los colonos de los resultados de las cosechas, precisamente porque estos se constituyeron en clientes y acreedores de aquéllos, que de diversas maneras los financiaban. Vinculados en los avatares de la producción cerealera, fueron conformando un nexo inextricable del comercio con la empresa agrícola, como consecuencia de la operatoria crediticia tanto en efectivo como diversos efectos, herramientas, alimentos o granos para la siembra. ${ }^{116}$

En este carácter o condición, si bien algunos comerciantes observaron un proceder atinado, imponiendo tasas de interés usuales de acuerdo con las cambiantes situaciones de la respectiva plaza, sin obligar con cláusulas leoninas, ${ }^{117} \mathrm{en}$ cambio otros aplicaron intereses usurarios, acentuados de manera singular luego de la crisis de 1890.

$\mathrm{Al}$ respecto, en Río Cuarto determinados préstamos pactados con garantía hipotecaria durante la década de 1880, mantuvieron tasas de

\footnotetext{
del Banco de la Provincia de Córdoba 1880-1895”, Revista de Economía y Estadística, Universidad Nacional de Córdoba, Facultad de Ciencias Económicas, Córdoba, 1990.

${ }^{115}$ Beatriz I. Moreyra, La producción agropecuaria cordobesa 1880-1930, Centro de Estudios Históricos, Córdoba, 1992, p. 340.

${ }^{116}$ AHPC, 1903, Juzgado 1a. Nominación Comercial, leg. 8, exp. 5 y leg. 11, exp. 3.

${ }^{117}$ Es el caso de Juan y Vicente Jorba con establecimiento mercantil en Río Cuarto, que en la década de 1880 prestaban a un interés de 10 a 12\% anual. AHPC, 1903, Juzgado 1a. Civil de Río Cuarto, leg. 9, exp. 4. En tanto que entre 1894 y 1896, aplicaban una tasa de 6 a $9 \%$ anual. AHPC, 1899, Juzgado 1a. Civil Río Cuarto, leg. 6, exp. 1.
} 
interés fijadas entre 10 y $12 \%$ anual, acrecentándolas a partir de 1890, año en que llegaron a $24 \%$ anual, pagaderos por trimestre vencidos. ${ }^{118}$

Estos altos intereses se aplicaron -con variaciones- hasta 1898, cuando las tasas fijadas oscilaban entre 15 y $18 \%$ anual. ${ }^{119}$ Tasas similares a las cobradas en la plaza de Bell Ville, del departamento Unión, con cláusulas que estipulaban la amortización por semestres adelantados, ${ }^{120}$ causaron no pocos inconvenientes al tomador del crédito.

Otra variante para imponer condiciones precautorias y a la vez especulativas, aprovechando circunstancias temporarias posibles de ofrecer grandes ventajas, resultó la práctica del descuento o cobro adelantado, es decir, con antelación a la entrega del dinero acordado, pactándose tasas de interés que alcanzaron $10 \%$ mensual. ${ }^{121}$

En tanto que, en las operatorias de corto plazo durante la última década del siglo XIX, la tasa oscilaba entre 2 y $5 \%$ mensual, de acuerdo con denuncias de especulación realizada en los departamentos del oeste cordobés. ${ }^{122}$

En ciertas plazas del departamento Tercero Arriba, en particular Villa Nueva y Villa María, se anotaron a fines de la década de 1890 operaciones crediticias pactadas con cláusula de garantía hipotecaria a tasas de interés usuales en la época. ${ }^{123}$ Pero este estilo cambió al comenzar el siglo $\mathrm{xx}$, retrotrayendo las tasas a las exigidas en los años inmediatamente cercanos a la crisis de 1890 , las que oscilaron entre 15 y $24 \%$ anual. ${ }^{124}$

Precisamente, como consecuencia de la cláusula de garantía hipotecaria, se registró en los casos de deudas la apropiación de inmuebles por parte del prestamista. ${ }^{125}$

Además, se practicaron pactos de retroventa que obligaron al tomador del crédito a entregar al prestamista la propiedad del inmueble hipotecado, generalmente subvaluado para adecuarlo al monto prestado. A resultas de estos acuerdos, el prestamista retenía la propiedad por el tiempo que transcurriese hasta satisfacer la deuda, cumplida ésta, el bien raíz volvía a su antiguo dueño. Esta modalidad se constituyó en la forma más

${ }^{118}$ AHPC, 1892, Juzgado 1a. Civil de Río Cuarto, leg. 2, exp. 15.

${ }^{119}$ Ibid., leg. 5, exp. 15, registro 6; 1896, leg. 9, exp. 3, registro 22; 1898, t. 5, f. 332.

${ }^{120}$ AHPC, 1891, registro 9, t. 10, f. 199.

${ }^{121}$ Ibid., 1886, Juzgado 1a. Civil Río Cuarto, leg. 2, exp. 11; 1891, leg. 5, exp. 5; El Porvenir, Río Cuarto, 5 de julio de 1899, núm. 48.

${ }^{122}$ Los Principios, Córdoba, 10 de enero de 1903, núm. 2341.

${ }^{123}$ AHPC, 1892, registro 11, t. 5, f. 265; 1899, t. 20, f. 48.

${ }^{124}$ Ibid., registro 28 , t. 4, fs. $79-80,84,98$; registro 11, t. 20 , f. 212.

${ }^{125}$ Se llegó al extremo de concretar una dación de nueve inmuebles a cambio de una garantía de un tercero. AHPC, 1892, registro 7, t. 10, f. $285 ; 1897$, t. 5 , f. 83 , Juzgado 1a. Civil de Río Cuarto, 1895, leg. 1, exp. 6. 
expeditiva de garantizar la suma prestada, y posibilitó también en definitiva una manera de apropiación inmobiliaria por deudas. ${ }^{126}$

En zonas con incidencia de la producción cerealera en el comercio, se acostumbró pactar el pago al prestamista con el trigo cosechado, es decir, se practicaba el pago de la deuda en especie, estableciendo dos cotizaciones diferentes, la fijada para los casos en que se cancelaba el préstamo antes de la cosecha, con un precio menor al corriente en la plaza, aumentándose éste ante la falta de concreción de la anterior posibilidad. ${ }^{127}$

Respecto a este tipo específico de operaciones financieras, conviene señalar que diseñaron específicas pautas de garantía, y por otra parte, revelan una operación especulativa montada por la casa acopiadora de cereales que usualmente cargaba al tomador del crédito con una tasa de interés anual de $12 \%$, pero mediante las estipulaciones inherentes a las cotizaciones aludidas, la alícuota, en realidad, se acordaba a porcentajes más elevados.

\section{CONCLUSIONES}

En orden a la moneda, las plazas regionales debieron sortear los inconvenientes generados en los efectos de la diversidad de los usos monetarios -sobre todo la de papel y la de plata-, las equivalencias entre la moneda nacional, las de circulación regional y los billetes de emisión local. Agregándose a estas cuestiones las secuelas de las fluctuaciones y de las rupturas del nivel cambiario, que produjeron indefensiones económicas no siempre superadas.

Los primeros permanecieron vigentes en Córdoba hasta mediados de la década de 1880 , junto a las dificultades que provocaba la periódica merma del circulante.

Por otra parte, la diversidad de usos monetarios generó desconfianza en la utilización del billete papel -que en algunos sectores se presentó con rasgos acentuados-, exteriorizando conductas proclives a menospreciar este medio de pago y a preferir la moneda metálica.

Las alzas en el valor de cambio del oro incidieron notablemente en las operaciones de compra y venta de la producción extranjera, provocando dificultades a la amortización de las mismas con dicha moneda. Consecuencia explicable, porque el tipo de cambio, en definitiva, es un

${ }^{126}$ AHPC, 1897, registro 10, t. 13, f. 16; 1893, registro 20, t. 2, f. 244; registro 11, t. 7, f. 451.

${ }_{127}$ Ibid., registro 9, t. 23, f. 382; Carlomagno Hnos. de Bell Ville, prestaba previo acuerdo con estas condiciones. 
precio de una moneda en términos de otra, que determina la posición competitiva de los productos en los distintos mercados, en los nacionales o en los extranjeros.

Asimismo complicó las transacciones pactadas entre los comerciantes mayoristas y sus clientes instalados en otras plazas, que afectadas por los vaivenes monetarios sufrieron la disminución de sus ventas $\mathrm{y}$, en consecuencia, el menoscabo del cumplimiento en los créditos tomados al adquirir mercancía a precios que oscilaron al unísono con las secuencias de alza o de baja referidas.

Respecto al crédito vinculado al comercio y al capital mercantil, se ha tratado de hacer un somero análisis siguiendo una rápida revisión de la interesante función cumplida por las instituciones financieras no bancarias y semibancarias que actuaban como canales por los que se trasladaban los fondos entre quienes tenían un excedente de cierto grado, a aquellos que necesitaban un crédito. Algunas de éstas fueron formaciones comerciales intermediarias que conectaron a las distintas partes de un sistema financiero endeble.

Más distanciados de este sistema se encontraban los establecimientos domésticos, familias y negocios que utilizaron o intervinieron en la demanda especulativa, pero no tomaron parte formal del conjunto operativo.

Por lo que atañe a las finanzas, en las variadas formas del crédito revisadas no sólo puede encontrarse un vínculo con el capital comercial y de éste con los emprendimientos productivos, además generalmente se presenta acompanado por tendencias especulativas y algunas facetas plenamente usurarias, sobre todo se evidencia en las transacciones pactadas entre particulares.

En cuanto al crédito bancario, existen evidencias de preferente atención respecto de los agentes del mercado, en tanto se desatendían los requerimientos del sector productivo.

La idea que condicionó al dinero como una mercancía pasible de uso especulativo y usurario se explicitó durante el decenio de 1850, reconociendo su vigencia en el anterior y permaneció en la práctica operatoria durante las décadas posteriores. 